a challenge to their autonomy, but we have to do what's right for patients and what's right for the health care system."

Evidence suggests, for instance, that physicians are far more likely to order a test if they own the machine needed to perform it, notes Matthews. There is also a tendency among some doctors to order expensive tests prematurely. "We do know that some physicians were sending people with lower back pain for MRIs before doing anything else," says Matthews.

Academics who have studied processes for determining what is medically necessary tend to agree that clinicians shouldn't be the only ones involved. Though medical expertise is of course required, the reality is that money comes into play as well. Every public dollar spent on health care, after all, is a dollar that can't be spent to provide other types of services to citizens. And nobody expects doctors to make decisions about patient care based on how it will affect, say, teachers' salaries.

"There really is a role for people other than doctors in the process," says Mark Stabile, director of the School of Public Policy and Governance and professor of economics and public policy at the Rotman School of Management of the University of Toronto in Ontario.
Efforts to contain costs don't necessarily detract from the quality of health care, Stabile says. In fact, more efficient care can sometimes be better care, even if physicians are reluctant to accept outside influence on how their practices should be run.

"Everybody would prefer to have nobody interfere with them, but there is some evidence, a lot of it from the United States, that when doctors are shown they can do a job better by making some adjustments, in the long run they are happier," says Stabile.

According to some observers, bringing a wider range of experts into the mix is long overdue. "Doctors have had the reins completely on deciding what is medically necessary and what is not, and that is increasingly going to have to come under scrutiny," says Colleen Flood, a law professor at the University of Toronto and a Canada Research Chair in Health Law and Policy. 'It's beholden on governments, who are spending public money, to take a look. ... The government obviously has to be involved in the sense that they set the budgets. Who else is going to represent the public interest if not them?'

Others who might be able to provide valuable input to the process include ethicists, scientists, public policy experts and philosophers, says Flood. Members of the public should also have a voice, though questions remain about how and when they should be involved.

"At what point, given the historical and political complexities inherent in medicare, could (and should) the public be involved?" Flood and colleagues have asked (www.law.utoronto.ca/sites /default/files/health_basket/docs/working 5_inandout.pdf). "What role could public values have in determining what services are publicly funded and which are left to the private sector?"

Whoever is involved, it is important that the process not merely be a bureaucratic exercise in saving money, says Flood. It must be a fair, reasonable process based on evidence. Most often, a decision regarding a particular test or procedure is not about whether it should be publicly funded - full stop - but rather about who really needs it and when is it necessary.

"We have to do this sort of thing to manage the health system," says Flood. "Individual doctors might not like having their decisions scrutinized, but why not? If you are making good decisions, why would you care?" Roger Collier, CMAJ

CMAJ 2012. DOI:10.1503/cmaj.109-4307

\title{
Medically necessary: How to decide?
}

I mplementing a process for making a decision based on defining a concept that may be indefinable can surprise, surprise - be rather complicated. Just ask those tasked with choosing which health services are "medically necessary." Yet, difficult as it may be, establishing a more explicit process for making that decision is viewed by many as a vital step in keeping Canada's health care system afloat.

And putting off the hard work required to establish such a process is probably a bad idea, considering that future advances in genetic medicine will only make the task more difficult, suggests Timothy Caulfield, a Canada Research Chair in Health Law and Policy at the University of Alberta in Edmonton.
"Being able to tailor therapies and treatments for individuals based on the personalized-medicine trend is going to complicate defining 'medically necessary' even more," says Caulfield.

Imagine, for instance, a physician informing Patient A that she is eligible for a particular therapy, then turning to Patient B, who has the same medical condition but isn't genetically predisposed to respond to the same treatment, and telling him that his provincial government will not cover the cost. This would likely go down as well as cod liver ice cream.

"It could in some ways be more precise, but it could become even messier," says Caulfield.

Of course, reluctance on the part of some health professionals to define cer- tain terms - "minimal," "adequate" and "required," to cite but a few ambiguous examples - should come as little surprise considering the many unsuccessful efforts to do so in the past. As for putting great effort into coming up with a tidy, all-encompassing definition of "medically necessary" — it's probably a waste of time, Caulfield has suggested (Health Law J 1996;4:63-85).

"There are those who believe a definition of this term, usually in the form of a list of services or as a basic benefits package, will provide a solution to certain health policy concerns. Both federal and provincial should resist pressure to adopt this approach," wrote Caulfield. "Given the history of the concept of 'medically necessary' and 
the numerous failed attempts to define it, a practical, operational and meaningful definition is likely unattainable."

A more productive approach would be to create a framework — based on evidence, costs and benefits — to guide decisions about publicly funded health services, suggests Colleen Flood, a law professor at the University of Toronto in Ontario and a Canada Research Chair in Health Law and Policy. Other countries already do this, notes Flood, citing New Zealand and Israel. In Canada, provinces have largely left decisions about the medical necessity of health services to physicians - a very different approach than used to decide which pharmaceutical products are covered under provincial formularies.

"When it comes to drugs, you see more explicit decision-making being taken," says Flood.

A more technical means of weighing the costs and benefits of any given health service is warranted, Flood and colleagues have suggested, because it's well known that little evidence of effectiveness exists for many services routinely recom-

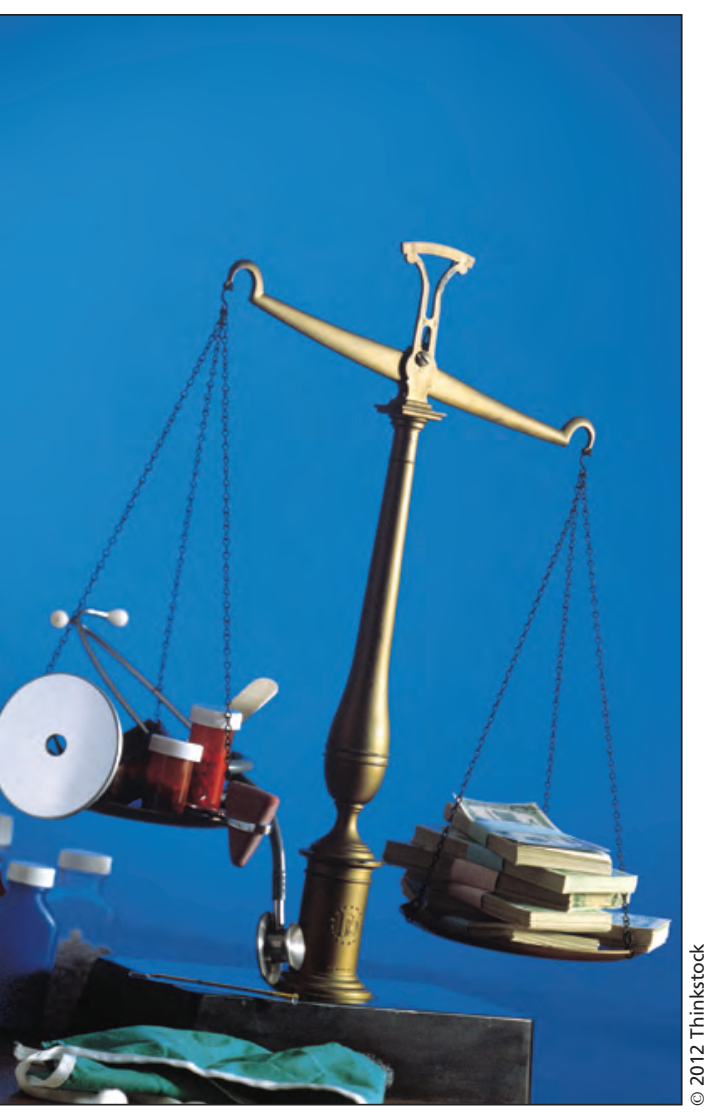

Trade-offs are inevitable in any system with limited resources. mended by physicians (http://dspace. cigilibrary.org/jspui/bitstream/123456789 /21334/1/What\%20is\%20In\%20and\%20 Out $\% 20$ of $\% 20$ Medicare $\% 20$ Who $\% 20$ Decides.pdf?1).

Without a formal process to evaluate the effectiveness of a service before deciding to fund it, provinces will find it very challenging to later reverse course. "If you let a new service proliferate and everybody gets used to it, it is very difficult to take it away," says Flood.

Though physicians will always have to make the day-to-day decisions about medical care, there is still a role for higher level decision-making involving those familiar with nonmedical matters, such as provincial health budgets, notes Flood. You can't make the trade-offs inevitable in any system with limited resources, after all, if you don't know how much money is available. It is important, however, that the process not merely result in a rigid list, but that it also considers when a given service is appropriate and for whom.

"Just saying yes or no - full stop isn't very helpful," says Flood. "What matters is that you have a fair process."

An important part of that process is determining which medical services should be delisted. These decisions are often unpopular, with both providers and partakers of delisted services, because it places emphasis on cost-effectiveness rather than only therapeutic value.

"The idea that this is only a medical decision, we have to let go of that," says Mark Stabile, director of the School of Public Policy and Governance and professor of economics and public policy at the Rotman School of Management at the University of Toronto. "We have to consider cost and effect."

In a study exploring the effects of delisting publicly funded medical services, Stabile and a colleague noted that resistance is to be expected (www.irpp .org/events/archive/nov05jdi/stabile.pdf). "Providers of those services will naturally be critical of the decision if they feel that the demand for their services will decline as a result of de-listings," states the paper. "In publicly funded systems, critics of privately financed health care systems will claim that any de-listing is the start of a 'decline' in publicly funded health care."
Still, it must be done if funding is to be made available for new, more-effective services. There are four important factors to consider when building a framework for assessing whether a medical service should be delisted, the paper suggests: If it provides not only medical value but also "a benefit per unit of cost that exceeds the next best alternative;" how delisting will affect demand; how changes in health outcomes due to delisting compare to the benefits gained by the money saved; and if delisting will disproportionately affect particular groups of people.

"Overall, our results suggest that policy makers should be aware that the demand response differs significantly by service and by individual characteristics," the paper concludes. "This information should be considered as services are considered for (continued) public funding."

Plans to implement a more explicit decision-making process to determine which medical services should be publicly funded have been put forward by at least one Canadian province. Ontario will be forming expert committees, comprised of practitioners and academics, to determine the medical necessity of certain services, such as magnetic resonance imaging for low back pain.

"I have made it very clear that we are going to be increasingly relying on evidence about what we will fund and what we won't fund," says Deb Matthews, Ontario's Minister of Health and Long-Term Care. "Our health care dollars are very precious. I don't want to spend those dollars on things that don't improve patient outcomes."

But the notion that a bureaucratic process can deem whether a medical service is necessary has been met with accusations of micromanagement from the Coalition of Family Physicians and Specialists of Ontario. Instead, the process should remain as it has been a discussion between a patient and a doctor, according to coalition president Dr. Douglas Mark. "It has to be individualized," says Mark. "The worst thing is putting them [the government] between us and the patient in making that decision." - Roger Collier, CMAJ

CMAJ 2012. DOI:10.1503/cmaj.109-4316 